\title{
Bacillus thuringiensis: características gerais e fermentação
}

\section{Bacillus thuringiensis: general characteristics and fermentation}

\author{
Elisangela Andrade Angelo ${ }^{1 *}$; Gislayne Trindade Vilas-Bôas²; \\ Raúl Jorge Hernan Castro-Gómez ${ }^{3}$
}

\begin{abstract}
Resumo
O controle de insetos é realizado, em sua maioria, por produtos químicos; cujos efeitos cumulativos ocasionam grandes prejuízos ambientais e à saúde humana, destacando-se ainda a rápida seleção de insetos resistentes. O controle biológico por entomopatógenos é uma alternativa eficiente, principalmente devido a sua alta especificidade, ausência de resistência nos insetos alvos e baixo efeito residual no ambiente. Bacillus thuringiensis é uma bactéria Gram-positiva esporulante, produtora de cristais protéicos com atividade inseticida. Apesar do amplo uso B. thuringiensis no controle biológico, há poucos trabalhos publicados quanto a sua multiplicação, esporulação e produção de cristais, visto que muitas informações são segredos industriais. Esta revisão teve por objetivo reunir informações gerais sobre $B$. thuringiensis, bem como quanto sua produção em meios de cultivo.
\end{abstract}

Palavras-chave: Bacillus thuringiensis, entomopatógeno, bioinseticida, controle biológico, fermentação

\begin{abstract}
The insect control is carried out mostly by chemical products, whose cumulative effects cause serious losses to environmental and human health, highlighting rapid selection of resistant insects. Biological control by entomopathogenic bacteria is an efficient alternative, mainly due to high specificity, absence of resistance in the target insects and low environment residual effect. Bacillus thuringiensis is a Grampositive spore-forming bacterium that produces a parasporal crystal protein toxic for many insect species. Despite the widespread use of B. thuringiensis based products in biological control of insects, there are little studies about its multiplication, sporulation and crystal production, as so many trade secrets information. This revision was aimed at gathering general information about $B$. thuringiensis, as well as its production in culture media.
\end{abstract}

Key words: Bacillus thuringiensis, entomopathogenic bacterium, bioinsecticide, biological control, fermentation

\footnotetext{
${ }^{1}$ Mestre em Ciência de Alimentos, Departamento Ciência e Tecnologia de Alimentos DCTA-CCA, Universidade Estadual de Londrina - UEL. E-mail: zanele77@gmail.com.br

${ }^{2}$ Professora Doutora do Departamento de Biologia Geral, Universidade Estadual de Londrina, UEL. E-mail: gvboas@uel.br

${ }^{3}$ Professor Doutor do Departamento Ciência e Tecnologia de Alimentos, Universidade Estadual de Londrina, UEL/CCA. E-mail: rcastro@yahoo.com

* Autor para correspondência
} 


\section{Introdução}

Estima-se que existam cerca de 2,5 milhões de espécies de insetos, das quais $10 \%$ causam danos ao ser humano ou perdas econômicas na pecuária ou na agricultura (ALVES, 1998). Muitas doenças de interesse da saúde pública, como malária, dengue, febre amarela, filariose e doença de Chagas são transmitidas por insetos vetores. Em geral, os países mais atingidos por estas doenças são os tropicais e subtropicais, devido principalmente às suas características climáticas favoráveis à proliferação de insetos. O crescente aquecimento global demanda preocupação especial, estendendo às áreas propícias a esta proliferação também a regiões atualmente com clima temperado (ABDEL-HAMEED, 2001; BECKER; MARGALIT, 1993; TALUIL, 2002).

O controle atual da população de insetos é realizado, principalmente, por inseticidas químicos, cujo uso indiscriminado e massivo causa danos ambientais e à saúde humana. Produtos químicos com alta toxicidade, porém com baixa especificidade e alto efeito residual, prejudicam o meio ambiente, além de contribuírem para a existência de considerável número de espécies de insetos com populações resistentes, inviabilizando a aplicação de tais produtos (ALVES, 1998; ARANTES et al., 2002).

Uma alternativa aos inseticidas químicos é o controle biológico, que pode ser feito com o uso racional de entomopatógenos, que constituem os componentes ativos dos bioinseticidas ou inseticidas biológicos. Entre as vantagens dos bioinseticidas destacam-se: alta especificidade, menor risco ambiental e à saúde humana, menor freqüência de resistência nos insetos alvo e a possibilidade do entomopatógeno se multiplicar no ambiente e, com isso, aumentar sua permanência. Como desvantagem principal destaca-se maior suscetibilidade às condições ambientais, o que pode ser atenuado com o uso de boas formulações e estudos para aplicação dos produtos, a fim de torná-los mais resistentes às condições ambientais e com maior tempo de prateleira (ALVES, 1998).
A comercialização de bioinseticidas corresponde a cerca de $5 \%$ do mercado mundial de pesticidas. Porém, o uso destes produtos vem crescendo dez vezes mais do que o uso de inseticidas químicos (BRAR et al., 2006). As bactérias destacam-se como promissoras no controle biológico. Entre estes microrganismos, Bacillus thuringiensis (Bt) é o mais utilizado. Estima-se que os produtos à base dessa bactéria correspondam a cerca de $90 \%$ do mercado mundial de bioinseticidas (VILASBÔAS; PERUCA; ARANTES, 2007). Os maiores produtores de produtos à base de $B$. thuringiensis são Estados Unidos e Canadá, que respondem por cerca de 50\% da produção mundial (TAMEZGUERRA et al., 2001).

OBrasil é um país de clima tropical cuja economia é bastante ligada à agricultura, onde insetos causam perdas substanciais na produção alimentar, além de serem vetores de uma variedade de doenças como dengue, malária e febre amarela (FORATTINI et al., 1995; SERUFO et al., 1993; TALUIL, 2002). $\mathrm{Na}$ sua maioria, o controle efetivo de insetos tem sido feito com inseticidas sintéticos, sendo pouco utilizados produtos à base de $B$. thuringiensis, uma vez que, no Brasil existe apenas uma única empresa que produz e comercializa formulações nacionais à base desta bactéria.

A maioria dos produtos à base de $B$. thuringiensis encontrados no mercado nacional é importada, o que causa aumento no preço final ao consumidor e conseqüente diminuição da competitividade destes produtos em relação a inseticidas sintéticos. Este quadro demonstra a necessidade de produção nacional de formulações à base de $B$. thuringiensis, os quais poderiam ser empregados em programas locais de controle de insetos, como sugerido por vários autores (COUCH; ROSS 1980; SALAMA; MARGALIT, 1993; ALVES et al., 1997; MORRIS; KANAGARATNAM; CONVERSE, 1997; VORA; SHETHNA, 1999; POOPATHI; KUMAR, 2003; PRABAKARAN; BALARAMAN, 2006).

A produção de formulações à base de $B$. thuringiensis passa por diversas fases como a 
escolha de uma linhagem geneticamente estável, altamente tóxica aos insetos alvo e que não apresente necessidades nutricionais exigentes para a sua produção em meio de cultivo, o que pode encarecer a produção. Após a seleção, é feito um estudo sobre sua produção em escala menor e posteriormente em grande escala. Concomitante a esses estudos ou após a otimização da produção, faz-se o estudo da formulação, a qual tem por objetivo aumentar a permanência do produto no ambiente onde será aplicado e facilitar sua aplicação. São feitos também testes da toxicidade do produto, tanto em condições de laboratório como em condições de campo (COUCH, 2000). Muitas informações referentes a esses estudos não são divulgadas, por serem segredos industriais dos produtores de bioinseticidas.

O objetivo desta revisão é apresentar aspectos gerais da biologia de $B$. thuringiensis, bem como de aspectos relacionados à sua produção.

\section{A base da entomopatogenicidade de Bacillus thuringiensis}

Bacillus thuringiensis foi descrito em 1915 na Alemanha, isolado a partir de traça de farinha (Anagasta kuehniella). Anteriormente, em 1902, no Japão, o pesquisador Ishiwata já havia isolado uma bactéria a partir de Bombyx mori, que posteriormente se soube ser também uma subspécie de $B$. thuringiensis. A comercialização do primeiro produto à base de $B$. thuringiensis foi iniciada em 1938 na França, com o nome de "Sporeine" (BRAR et al., 2006; CAPALBO; VILAS-BÔAS; ARANTES, 2004).

Pertencente à família Bacillaceae, a qual engloba a maioria das espécies formadoras de esporos, $B$. thuringiensis é um bastonete Gram-positivo, com célula vegetativa de 1,0 a 1,2 $\mu \mathrm{m}$ de largura por 3,0 a 5,0 $\mu \mathrm{m}$ de comprimento, geralmente móveis. $\mathrm{O}$ esporo dessa bactéria possui formato elipsoidal e localiza-se na região central ou paracentral quando no interior da célula-mãe. A espécie é aeróbia não estrita com faixa de temperatura de crescimento entre 10 e $45{ }^{\circ} \mathrm{C}$. B. thuringiensis apresenta um amplo complexo enzimático, o que lhe permite utilizar uma variedade de substratos. A principal característica que distingue a espécie das outras do mesmo gênero é a presença intracelular de um cristal protéico, cuja produção foi descoberta somente em 1953 por Hannay (GLARE; O'CALLAGHAN, 2000; HABIB; ANDRADE, 1998; MORAES; CAPALBO; ARRUDA, 2001; VILAS-BÔAS; PERUCA; ARANTES, 2007).

A produção de cristais protéicos representa uma característica típica de $B$. thuringiensis e, em geral, ocorre durante a esporulação. Estes cristais apresentam atividade entomopatogênica para várias espécies de insetos, destacando-se as Ordens dos lepidópteros, dípteros e coleópteros. Porém, há subespécies de $B$. thuringiensis que apresentam cristais tóxicos contra insetos das Ordens Himenoptera, Hemiptera, Orthoptera, Phthraphera e também para alguns nematóides, protozoários e ácaros (BRAR et al., 2006; GLARE; O'CALLAGHAN, 2000; SCHNEPF et al., 1998).

Os cristais de $B$. thuringiensis são formados principalmente por proteínas denominadas Cristal (Cry), antigamente conhecidas como $\delta$-endotoxinas (BRAVO; GILLB; SOBERÓN, 2007). Ao final da esporulação, o cristal protéico corresponde a cerca de $20 \%$ a $30 \%$ do peso seco da célula, sendo liberado no momento da lise celular (ARANTES et al., 2002; GLARE; O’CALLAGHAN, 2000).

\section{Proteínas Cry}

As proteínas Cry são consideradas como os principais constituintes dos cristais que caracterizam B. thuringiensis, são codificadas por genes que geralmente se localizam em plasmídios e, com menor freqüência, no cromossomo bacteriano. Atualmente estão descritas 436 proteínas Cry, sendo que a cada ano novas proteínas são descobertas. Somente no ano de 2008 foram descritas 42 novas proteínas (CRICKMORE et al., 2008). Existe um banco de dados on-line que, periodicamente, atualiza 
a classificação e nomenclatura das proteínas Cry (CRICKMORE et al., 1998, 2008). De acordo com a definição mais aceita, uma proteína é considerada Cry, quando forma uma inclusão paraesporal (cristal) em B. thuringiensis, exibe algum grau de toxicidade a insetos alvos, ou apresente seqüência de aminoácidos similar a uma proteína Cry já descrita (BRAVO; GILLB; SOBERÓN, 2007; SCHNEPF, et al, 1998).

As proteínas Cry são sintetizadas na forma de protoxinas. Desta forma, sua ação depende de processos de ativação, que ocorrem no interior do aparelho digestório do inseto. Atualmente, há dois modelos, baseados em dados experimentais, que explicam o modo de ação das toxinas Cry. As primeiras etapas desses dois modelos são idênticas: após a ingestão dos cristais, esses são solubilizados no intestino do inseto, local com $\mathrm{pH}$ alcalino, liberando as protoxinas que são clivadas por proteases do próprio inseto, resultando em toxinas ativas, com cerca de 60 a $70 \%$ do tamanho da protoxina. A toxina ativa é capaz de ligar-se a receptores específicospresentesnasmicrovilosidades das células intestinais do inseto (BRAVO; GILLB; SOBERÓN, 2007; SCHNEPF, et al., 1998).

O modelo de ação denominado "formação de poros" é o mais antigo e parece ser o mais comum entre as diferentes ordens de insetos (Dípteros, Lepidópteros e Coleópteros). Segundo esse modelo, a ligação da toxina com receptores específicos levaria a formação de oligômeros de toxinas, os quais se ligariam a receptores secundários da membrana da célula intestinal. Como resultado dessa ligação, ocorreria a inserção da toxina oligomérica na membrana da célula epitelial intestinal, resultando em poros nesse epitélio (BRAVO; GILLB; SOBERÓN, 2007; BRAVO; SOBERÓN, 2008; HABIB; ANDRADE, 1986).

Outro modelo, recentemente publicado, é denominado "transdução de sinal" e foi estudado em apenas poucos insetos-alvos. De acordo com esse modelo, a ligação da proteína Cry com receptores específicos, induziria uma série de reações intracelulares, que envolvem a proteína $\mathrm{G}$ e a adenilato ciclase, resultando no aumento da concentração de adenosina monofosfato cíclico (AMPc) intracelular e ativação da proteína quinase A. Todas essas conseqüências provocariam um desequilíbrio da pressão interna celular, danificando-a (BRAVO; SOBERÓN, 2008).

A ação das toxinas, seja por qualquer um dos modelos, resulta na paralisia do aparelho digestório, ocasionando morte por inanição, paralisia geral dos músculos e septicemia (BRAVO; GILLB; SOBERÓN, 2007; BRAVO; SOBERÓN, 2008; HABIB; ANDRADE, 1986; VALLETE-GELY; LEMAITRE; BOCCARD, 2008).

A formação de proteínas Cry é determinada por genes denominados cry e uma mesma linhagem de B. thuringiensis pode conter um único gene cry ou várias cópias de um mesmo gene, ou mesmo vários genes cry diferentes, determinando a formação de diferentes proteínas Cry, que podem compor um ou mais cristais intracelulares. Grande parte dos genes cry localiza-se em plasmídeos grandes, freqüentemente conjugativos, o que pode possibilitar a passagem destes plasmídeos de uma linhagem para outra, resultando na formação de linhagens com uma grande diversidade de perfis de toxicidade (CAPALBO; VILAS-BÔAS; ARANTES, 2004; LERECLUS; DELÉCLUSE; LECADET, 1993).

A transcrição da maioria dos genes cry é dependente do fator sigma, produzido durante o processo de esporulação, por isso a maior parte das proteínas que compõem o cristal é produzida durante essa etapa. Apenas uma pequena parcela dos genes cry é regulada independentemente da esporulação, sendo, portanto, expressos também durante o crescimento vegetativo. Em ambos os casos, a proteína Cry é fruto do metabolismo secundário (ARANTES et al., 2002; LERECLUS; DELÉCLUSE; LECADET, 1993).

A massa molecular das proteínas Cry varia entre 40 e $140 \mathrm{KDa}$. A molécula destas proteínas 
é globular, formada por três domínios estruturais ligados entre si por pequenas pontes. Até o momento, seis proteínas Cry tiveram suas estruturas bem determinadas por cristalografia por raios-X (BRAVO; GILLB; SOBERÓN, 2007). Estas proteínas apresentam alto grau de similaridade entre seus domínios, indicando modo de ação similar. $\mathrm{O}$ domínio I, composto pela extremidade N-terminal das proteínas, é formado por cadeias polipeptídicas com estrutura em $\alpha$-hélice, sendo uma central (hidrofóbica), cercada por 6 cadeias marginais. $\mathrm{O}$ domínio II é composto por três cadeias polipeptídicas antiparalelas com estrutura folha $\beta$ pregueada, enquanto que o domínio III apresenta estrutura tipo $\beta$ sanduíche (BRAVO; GILLB; SOBERÓN, 2007).

Embora estudos atuais indiquem que várias porções dos diferentes domínios da proteína se insiram na membrana no momento de formação dos poros, acredita-se que o domínio I seja o principal responsável pela inserção (NAIR; DEAN, 2008). Os domínios II e III apresentam similaridades estruturais com cadeias polipeptídicas que se ligam a carboidratos e estariam envolvidos principalmente no reconhecimento de receptores presentes na membrana das células dos insetos-alvo (BRAVO; GILLB; SOBERÓN, 2007).

\section{Proteínas Cyt}

As proteínas Cyt são definidas como proteínas com atividade hemolítica que compõem uma inclusão paraesporal de $B$. thuringiensis, ou alguma proteína que apresente seqüência de aminoácidos altamente similar às proteínas Cyt já descritas. Estas proteínas apresentam uma similaridade estrutural com a valvatoxina, produzida pelo fungo Volvariella volvacea. As proteínas Cyt são formadas por apenas um domínio, composto por duas cadeias externas em forma de $\alpha$-hélice, e uma cadeia interna em forma de $\beta$-folha pregueada. Atualmente são conhecidas 27 proteínas Cyt (BRAVO; GILLB; SOBERÓN, 2007; CRICKMORE et al., 1998, 2008), classificadas em grupos principais: Cyt1A,
Cyt1B, Cyt1C, Cyt2A e Cyt2B. O mesmo comitê responsável pela classificação das proteínas Cry, também gerencia a classificação e nomenclatura das proteínas Cyt (CRICKMORE et al., 2008).

Assim como as proteínas Cry, as Cyt também são sintetizadas na forma de protoxinas. No interior do inseto, as proteínas Cyt sofrem quebras, onde suas porções C-terminal e N-terminal são clivadas, liberando a toxina ativa. Ao contrário das proteínas Cry, Cyt não se liga a receptores específicos da membrana celular, e sim, diretamente aos lipídios da membrana. Após sua ligação, as proteínas Cyt induzem a formação de poros ou agem desestruturando a bicamada lipídica das membranas (BRAVO; GILLB; SOBERÓN, 2007).

Vários estudos têm demonstrado ocorrer um efeito sinergístico entre as proteínas Cry e entre estas e as proteínas Cyt, ou seja, a maior toxicidade é devida à interação das proteínas, onde uma potencializa o efeito da outra (BRAVO; GILLB; SOBERÓN, 2007; ÖSKAN et al., 2003).

\section{Outras toxinas produzidas por B. thuringiensis}

Além das proteínas Cry e Cyt, B. thuringiensis sintetiza outras toxinas que podem contribuir para a ação entomopatogênica. Em 1967 Heimpel sugeriu o nome de $\beta$-exotoxina para uma substância termoestável e tóxica para alguns insetos. Devido a sua estrutura química o nome $\beta$-exotoxina vem sendo substituído por thuringiensina. Essas proteínas possuem baixo peso molecular, a sua toxicidade relaciona-se a inibição da RNA polimerase, pois é análoga a nucleotídeos. Embora não possua especificidade, a ação de thuringiensina contribui para a toxidade global das linhagens que a expressam (GLARE; O'CALLAGHAN, 2000; HABIB; ANDRADE, 1998; LERECLUS; DELÉCLUSE; LECADET, 1993). Alguns trabalhos citam a importância dessa toxina no controle de besouros e algumas espécies de ácaros (WU et al., 2002). No entanto, as linhagens comerciais de $B$. thuringiensis 
não devem produzir esta toxina, pois ela poderia ocasionar efeitos adversos em organismos não alvos.

Muitos sorotipos de $B$. thuringiensis produzem proteínas denominadas Vip (vegetative insecticidal proteins), as quais são sintetizadas na etapa vegetativa do crescimento. Essas proteínas foram descritas por Estruch et al. em 1996. Apesar de não integrarem o cristal protéico, elas contribuem para a toxicidade global das linhagens que as apresentam e possuem forma de intoxicação similar às das proteínas Cry (CRICKMORE et al., 2008; GLARE; O'CALLAGHAN, 2000). Alguns trabalhos relatam a importância das proteínas Vip na ação inseticida contra coleópteras (Vip1 and Vip2) e lepidópteras (Vip3), as quais parecem intensificar a ação das proteínas Cry (ESTRUCH et al., 1996; CHEN; HONG; WU., 2003; SHI et al., 2004). Os estudos de Yu et al. (1997) indicam que o principal modo de ação das proteínas Vip resulta na ruptura das células do intestino, sendo essa a forma de ação primária dessas toxinas.

No mesmo site onde se encontra a classificação das proteínas Cry e Cyt, pode ser encontrada também a classificação e nomenclatura das proteínas Vip (http://www.lifesci.sussex.ac.uk/home/Neil_ Crickmore/Bt/vip.html).

Em acréscimo às proteínas Cry, Cyt e Vip, no ano 2000, Mizuki et al. descreveram uma nova toxina em uma linhagem de $B$. thuringiensis a qual passou a ser denominada Parasporina. Este termo é definido como uma proteína paraesporal de $B$. thuringiensis e bactérias relacionadas, sem atividade hemolítica e que apresentam a capacidade de atacar células cancerígenas em geral (OHBA et al., 2008). Atualmente existem 14 paraesporinas diferentes, classificadas em quatro grupos PS1A a PS4A. A nomenclatura destas proteínas segue os mesmos critérios adotados para as proteínas Cry e Cyt e um comitê fundado no ano de 2006 determina a classificação e a nomenclatura de novas parasporinas (http://parasporin.fitc.pref.fukuoka.jp/ index.html).
Além das toxinas, o esporo de $B$. thuringiensis também contribui para sua toxicidade, pois estes podem germinar no interior do inseto-alvo, ocasionando septicemia; ou potencializando o efeito das toxinas em uma ação sinergística (GLARE; O'CALLAGHAN, 2000; RAYMOND et al., 2008).

\section{Produção de $B$. thuringiensis}

\section{Etapas da produção}

Embora a produção de $B$. thuringiensis seja bem estudada, há poucos dados na literatura a esse respeito, visto que muitas informações são segredos industriais. Em geral, os produtos à base de $B$. thuringiensis são compostos por uma mistura de cristais, esporos, poucas células vegetativas e ingredientes secundários da formulação (CAPALBO; VILAS-BÔAS; ARANTES, 2004). As principais etapas para a produção de $B$. thuringiensis são: seleção da linhagem, estocagem, processo fermentativo, recuperação do princípio ativo (esporos e cristais), formulação do produto e análise da qualidade (MORAES; CAPALBO; F; ARRUDA, 2001; COUCH, 2000).

Segundo Couch (2000) os principais critérios para seleção de uma subespécie bacteriana para produção de bioinseticidas são: espectro de ação, potência por unidade de volume da cultura, requerimentos nutricionais, facilidade de produção, estabilidade genética e facilidade de estocagem.

A estocagem apropriada é de grande importância, pois a linhagem deve conservar seu potencial tóxico e velocidade de crescimento. No caso de B. thuringiensis, as trocas de plasmídios ocorrem com certa freqüência e há relatos de perda de toxicidade após sucessivas fermentações, sendo essencial a constante busca por novas linhagens e o monitoramento durante o processo de fermentação (COUCH, 2000; BIZARRI et al., 2008).

A forma mais comum de produção de $B$. thuringiensis é por fermentação submersa (líquida) descontínua, também conhecida como processo 
em batelada. Nesta fermentação, um recipiente contendo meio de cultura líquido é inoculado com o microrganismo, não havendo acréscimo ou retirada significativa do meio fermentado. Portanto, ocorre todo o desenvolvimento da cultura, sendo retirado o produto apenas no final do processo. Em geral, as proteínas Cry de $B$. thuringiensis são formadas no fim da fermentação, quando as condições do meio se tornam desfavoráveis, sendo o processo em batelada satisfatório para tal produção (MORAES; CAPALBO; ARRUDA, 2001).

Alguns pesquisadores têm estudando as fermentações sólida, contínua e em batelada alimentada, porém até o momento, o mais viável para produção de proteínas Cry ainda é o processo em batelada submersa (ADAMS; EITENAN; HANEL, 2002; CHEN; HONG; WU, 2003, MORAES; CAPALBO; ARRUDA, 2001; VALLEJO et al., 1999).

$\mathrm{Na}$ fermentação industrial os passos a serem seguidos são: pré inóculo, geralmente feito em frascos pequenos, pré fermentador, comumente com $1 / 5$ do volume da fermentação e o fermentador final. Durante todas as etapas deve-se analisar a cultura quanto à contaminação, características morfológicas e potencial entomopatogênico. Em geral, os reatores utilizados permitem o controle das condições principais de cultivo, as quais são: temperatura, $\mathrm{pH}$, aeração e agitação. O pré-inoculo, pré-fermentador e o fermentador em volumes crescentes são feitos a fim de diminuir o tempo da fase lag, ou seja, o período de adaptação do microrganismo às condições de cultivo. Em geral, pré fermentadores e fermentador possuem os mesmos ingredientes no meio de cultivo. É importante limitar o número de passos no processo de produção a fim de evitar contaminações e mudanças indesejáveis no comportamento da bactéria (COUCH, 2000; MORAES; CAPALBO; ARRUDA, 2001).

Ao final da fermentação, a cultura de $B$. thuringiensis apresenta em média 6 a $8 \%$ de sólidos, sendo que os esporos e cristais podem corresponder até a metade deste total. Há vários métodos que podem ser utilizados para a recuperação destes cristais e esporos, sendo a centrifugação e a microfiltração os mais comuns. É importante ressaltar que tais processos permitem a recuperação principalmente das proteínas Cry. Muitas outras toxinas que podem contribuir para a toxicidade final do produto são perdidas. Atualmente novas técnicas de recuperação e/ou concentração do produto estão sendo desenvolvidas para complementar as mais utilizadas, destacando-se: a liofilização e a flotação (BRAR et al., 2006; COUCH, 2000).

Após a recuperação dos metabólitos de interesse, os produtos são formulados. No caso dos bioinseticidas, a formulação tem três objetivos principais: conferir estabilidade ao produto durante a estocagem e aplicação, facilitar a aplicação do produto e proteger o microrganismo e os cristais das condições adversas do ambiente (BRAR et al., 2006; $\mathrm{COUCH}, 2000)$. Embora sejam segredos industriais, os produtos formulados geralmente contam com uma combinação de aditivos reconhecidos pela USA/FDA (Food and Drug Administration) ou pelo órgão competente do país. É comum o uso de dispersantes, protetores e surfactantes (GLARE; O'CALLAGHAN, 2000; BRAR et al., 2006).

Antes de ser comercializado, o produto formulado deve passar por testes de análise de qualidade que atestem principalmente sua potência tóxica. Para B. thuringiensis, a toxicidade é geralmente analisada por meio de bioensaio com o inseto-alvo (COUCH, 2000). Além dos testes de toxicidade, os bioinseticidas comercializados devem passar por uma série de testes que assegurem sua segurança ambiental e à saúde humana. Em geral, são feitos testes com mamíferos sadios e imune-suprimidos, os quais são submetidos à exposição dérmica, ocular, inoculação intraperitoneal e subcutânea. Em relação à inocuidade ambiental, são feitos testes para avaliar a toxicidade dos produtos sobre aves, vertebrados aquáticos, invertebrados, incluindo insetos não-alvo, vegetais e até mel de abelhas. Estes ensaios de toxicidade não devem indicar efeitos 
adversos significativos nos organismos testados, o que garante a segurança ambiental dos produtos (VILAS-BÔAS; PERUCA; ARANTES, 2007). Nos Estados Unidos, esses testes são regulamentados pela Agência de Proteção Ambiental (US-EPA) e departamento de agricultura dos estados, os quais exigem uma licença para que o produto seja comercializado. No Brasil, essa licença é expedida pela ANVISA (Agência Nacional de Vigilância Sanitária), a qual também exige testes padrões para liberação da comercialização do produto.

\section{Meios de cultura}

A escolha do meio de cultivo adequado é extremamente importante para o sucesso de um produto. Esta escolha deve proporcionar a máxima produção com o mínimo custo (COUCH, 2000). Os meios de cultivo para $B$. thuringiensis geralmente possuem uma fonte de nitrogênio, outra de carbono e sais minerais. Algumas vezes se adicionam ao meio alguns tampões e anti-espumantes a fim de facilitar o processo. A fonte de carbono, além de fornecer matéria prima para muitos compostos celulares, serve como fonte de energia. O nitrogênio é requerido principalmente para síntese de proteínas e ácidos nucléicos. Os sais minerais atuam como co-fatores, sendo também importantes no controle da osmolaridade celular.

Couch (2000) cita os principais componentes e suas concentrações utilizadas no cultivo de $B$. thuringiensis na América do Norte (Tabela 1). Apesar das indústrias não revelarem a composição de seus meios, sabe-se que estes geralmente são resultantes da combinação dos produtos listados. Muitos dos produtos utilizados são componentes indefinidos, porém não devem apresentar muita variação de um lote para outro.

Tabela 1. Principais ingredientes utilizados em meios de cultivo de bactérias entomopatogênicas e suas concentrações.

\begin{tabular}{lc}
\hline Ingrediente & Concentração $\mathbf{( g / L )}$ \\
\hline Farinha de soja & $20-40$ \\
Farinha da semente do algodão & $14-30$ \\
Proteína de batata & $15-40$ \\
Licor de milho ou sólidos derivados de milho & $15-30$ \\
Glicose & $10-30$ \\
Peptona & $2-5$ \\
Xarope de milho & $20-45$ \\
Melaço & $1.0-18.6$ \\
Glicerol & $2.0-10$ \\
Amido de milho & $10-15$ \\
Extrato de levedura & 2.0 \\
$\mathrm{KH}_{2} \mathrm{PO}_{4}$ & 1.0 \\
$\mathrm{~K}_{2} \mathrm{HPO}_{4}$ & 1.0 \\
$\mathrm{FeSO}_{4}$ & 0.02 \\
$\mathrm{FeSO}_{4} \cdot 7 \mathrm{H}_{2} \mathrm{O}$ & $0.0005-0.02$ \\
$\mathrm{MgSO}_{4} 7 \mathrm{H}_{2} \mathrm{O}$ & 0.3 \\
$\mathrm{MnSO}_{4} \cdot \mathrm{H}_{2} \mathrm{O}$ & 0.02 \\
$\mathrm{ZnSO}_{4} \cdot 7 \mathrm{H}_{2} \mathrm{O}$ & 0.02 \\
$\left(\mathrm{NH}_{4}\right)_{2} \mathrm{SO}_{4}$ & 2 \\
$\mathrm{CuSO}_{4} \cdot 5 \mathrm{H}_{2} \mathrm{O}$ & 0.005 \\
$\mathrm{CaCO}_{3}$ & $1.0-1.5$ \\
\hline
\end{tabular}

Fonte: Couch, 2000. 
Meios alternativos vêm sendo estudados a fim de baratear o produto final, principalmente nas produções regionais e em escala piloto. Vários autores obtiveram resultados satisfatórios com meios de cultivo empregando componentes alternativos: Poopathi et al. (2002) em cultivos em meio à base de batata, Vora e Shethna (1999) estudaram um meio contendo extrato de soja suplementado com cistina, e Prabakaran et al. (2008) desenvolveram um meio de cultivo à base de água de coco. No Brasil, a possibilidade de se utilizar meios alternativos apresenta um amplo potencial tendo em vista a diversidade natural e variabilidade da agroindústria.

Vários estudos têm sido feitos utilizando-se como meio de cultivo para $B$. thuringiensis águas residuais de indústrias e de estações de tratamento de água, tais trabalhos têm apresentado bons resultados, e muitas produções em escala piloto em várias regiões do mundo já utilizam tais resíduos (LACHHAB; TYAGI;VALÉRO, 2002; MONTIEL; TYAGI; VALERO, 2001; VIDYARTHI et al., 2002; YEZZA et al., 2005, 2006; CHANG et al., 2008).

A fonte de carbono para cultivo de B. thuringiensis varia muito conforme o objetivo da fermentação, bem como qual linhagem está sendo cultivada. A maioria dos trabalhos revela que a melhor fonte para crescimento vegetativo não corresponde à melhor fonte para esporulação e formação dos cristais protéicos (IÇGEN; IÇGEN; ÖZCENGIZ, 2002b; ÖSKAN et al., 2003).

Os estudos de Içgen, Içgen e Özcengiz (2002b) indicam um efeito inibidor de altas concentrações de glicose durante a síntese da $\delta$-endotoxina. De acordo com este trabalho, as melhores fontes de carbono para produção dos cristais tóxicos e esporulação são lactose, sacarose e inulina.

Segundo de Öskan et al. (2003), glicose, amido e melaço inibem a produção de proteínas Cry, em particular da proteína Cry4B (134KDa). Este estudo foi feito com $B$. thuringiensis subsp. israelensis e ressalta o efeito repressor da glicose, a qual agiria em etapas de fosforilação da proteína quinase Calfostina C, responsável pela produção das protoxinas Cry. Segundo os autores, as melhores fontes de carbono para biossíntese da $\delta$-endotoxina seriam dextrina, aveia, maltose, lactose, inulina, glicerol e sacarose, sendo a dextrina a mais promissora de todas quanto à esporulação e produção de toxina.

Resultados conflitantes aos deste trabalho foram obtidos por Vora e Shethna (1999) e Prabagaran et al. (2004), os quais indicam o melaço-de-cana como uma boa fonte de carbono para produção de toxina. Todos estes estudos, entre outros, comprovam que é necessário otimizar um meio para cada sorotipo, ou mesmo para cada linhagem, pois os resultados de estudos com um determinado sorotipo muitas vezes não podem ser extrapolados para outros.

As fontes de nitrogênio podem ser tanto orgânicas quanto inorgânicas, sendo comum a utilização conjunta das duas formas. Os estudos de Arcas, Yantoro e Ertola (1984), Içgen, Içgen e Özcengiz (2002b), Öskan et al. (2003) e Zouari e Jaoua (1999) indicam que o uso de apenas nitrogênio inorgânico não é aconselhável para o cultivo de $B$. thuringiensis, pois há diminuição de crescimento, esporulação e biossíntese, em relação aos meios com nitrogênio orgânico e inorgânico. Dentre as mais promissoras fontes de nitrogênio inorgânico apontadas por estes autores, destacam-se os fosfatos $\left[\mathrm{NH}_{4} \mathrm{H}_{2} \mathrm{PO}_{4}\right.$ e $\left(\mathrm{NH}_{4}\right)_{2} \mathrm{HPO}_{4}$ ], isto é, fosfato de amônia monobásico e dibásico, respectivamente, e sulfato de amônia por otimizarem esporulação e muitas vezes a produção de toxinas.

Entre as fontes orgânicas de nitrogênio, o extrato de levedura é bastante utilizado no cultivo de $B$. thuringiensis, porém peptona e derivados de soja apresentam resultados satisfatórios (VORA; SHETNA, 1999; IÇGEN; IÇGEN; ÖZCENGIZ, 2002b; MORRIS; DEAN, 1997). Como fontes alternativas, vêm se destacando farinhas derivadas de proteína animal (farinha de peixe e de crisálida) e alguns cereais (cevada e trigo) (ALVES et al., 1997; DEVI; RAVINDER; JAIDEV, 2005; GHRIBI; 
ZOUARI; JAOUA, 2005; MORRIS; DEAN, 1997; PRABAKARAN; BALAMARAN, 2006; ZOUARI; JAOUA, 1999).

A concentração de sais no meio de cultivo influencia diretamente a osmolaridade do mesmo. Entretanto, não há consenso sobre qual porcentagem de sais é mais adequada, bem como quais os sais que devem ser adicionados (ARCAS; YANTORO; ERTOLA, 1987; IÇGEN; IÇGEN; ÖZCENGIZ, 2002a; ÖSKAN; IÇGEN; ÖZCENGIZ, 2003).

Arcas Yantoro e Ertola (1987) obtiveram uma boa produção de toxina com um meio contendo osmolaridade de 808 miliosmol, tal trabalho é experimento clássico que resultou em um meio bastante adotado para crescimento e produção de $B$. thuringiensis. É importante ressaltar que embora os sais ajam como um todo na osmolaridade, cada íon fornecido pelos sais pode ter um efeito diferente. Muitas vezes, produção e crescimento não estão associados e a presença de alguns íons melhora um parâmetro e prejudica ou é neutra para outro.

Os estudos de Öskan et al. (2003) e Içgen, Içgen e Özcengiz, (2002a) revelaram que o manganês é crítico para a diferenciação celular, sendo requerido para esporulação e formação do cristal. Os melhores resultados aparecem quando a concentração de manganês varia entre $10^{-6}$ e $10^{-4} \mathrm{M}$, sendo que valores maiores que estes se tornam tóxicos para todos os processos celulares.

Assim como manganês, o magnésio influencia o metabolismo secundário, portanto, com efeito na produção das proteínas Cry. Sua concentração ideal é em torno de $10^{-3} \mathrm{M}$. O cálcio é bastante importante no processo de esporulação, promovendo a estabilidade do cristal protéico. A concentração de $10^{-3} \mathrm{M}$ de cálcio estimula a esporulação, porém é inibidora para o crescimento vegetativo e síntese protéica. Ao que parece, o cálcio não é essencial para a síntese das proteínas Cry. Desta forma, diversos estudos recomendam o uso de concentrações menores que $10^{-3} \mathrm{M}$ de cálcio, a fim de não comprometer a formação das proteínas Cry (IÇGEN; IÇGEN;
ÖZCENGIZ, 2002a; ÖSKAN et al., 2003).

Metais como zinco, cobre e ferro apresentam resultados negativos para o crescimento, esporulação e produção de toxina Cry mesmo em concentrações pequenas como $10^{-7} \mathrm{M}$ (IÇGEN; IÇGEN; ÖZCENGIZ, 2002a; ÖSKAN et al., 2003).

Tendo em vista a influência de diferentes variáveis, o desenvolvimento de meios de cultivo para a produção de $B$. thuringiensis é bastante complexo. Além disso, há uma variação muito grande de uma linhagem para outra, o que, muitas vezes, dificulta a extrapolação dos resultados de um trabalho. Ressalta-se nesse sentido, a necessidade de utilização de métodos de planejamento e otimização eficazes, como a metodologia de superfície de resposta, a qual leva em consideração vários fatores que influenciam em uma produção.

\section{Parâmetros físicos durante a fermentação}

Geralmente, os parâmetros monitorados durante o processo de fermentação são: temperatura, $\mathrm{pH}$ e taxa de oxigênio dissolvido. Sendo este último influenciado, principalmente, pelas taxas de aeração e agitação (COUCH, 2000).

O cultivo de $B$. thuringiensis é feito com temperaturas em torno de $30^{\circ} \mathrm{C}$, sendo que temperaturas superiores podem induzir a supressão da formação de proteínas Cry e conseqüente diminuição do rendimento. Da mesma forma, temperaturas inferiores desaceleram o ciclo de multiplicação celular, o que causa aumento no tempo e conseqüente custo da produção (MORAES; CAPALBO; ARRUDA, 2001; COUCH, 2000).

$\mathrm{O} \mathrm{pH}$ do processo fermentativo pode ser monitorado por eletrodos sensíveis a variações, os quais acionam reservatórios de ácidos ou bases a fim de manter o $\mathrm{pH}$ constante. Uma opção comumente empregada para inibir variações de valores de $\mathrm{pH}$ é o uso de soluções tampão. No entanto, há controvérsias, pois alguns estudos apontam que variações na faixa de $\mathrm{pH}$ podem proporcionar melhorias na produção, 
enquanto outros consideram estas variações prejudiciais (IÇGEN; IÇGEN; ÖZCENGIZ, 2002a). Essas variações nos valores de $\mathrm{pH}$ durante o cultivo de linhagens de $B$. thuringiensis em diferentes meios de cultivo já foi demonstrada anteriormente, como no estudo de Abdel-Hameed (2001), com o meio TYG-agar, à base de triptona, extrato de levedura e glicose e com $\mathrm{pH}$ inicialmente neutro. Neste estudo sem controle de $\mathrm{pH}$, a cultura apresentou redução nos valores de $\mathrm{pH}$ para valores ácidos no início da esporulação, seguindo-se de valores alcalinos no final do processo de fermentação (ABDELHAMEED, 2001).

A quantidade de oxigênio dissolvido no meio de cultura é dependente de diversos fatores como osmolaridade do meio, taxa de aeração e agitação (COUCH, 2000). Este é um fator bastante crítico para biossíntese das proteínas Cry por $B$. thuringiensis e deve ser bem analisado, pois em grandes volumes de fermentação o suprimento adequado de oxigênio torna-se ainda mais difícil e oneroso.

Segundo o estudo de Wu et al. (2002) a morfologia das células de $B$. thuringiensis ao microscópio óptico pode variar conforme as mudanças nos parâmetros de cultivo, com especial destaque para o suprimento de oxigênio, sendo que o excesso de aeração pode provocar uma desaceleração no ciclo de produção das proteínas Cry, por estender demais a fase de crescimento. Os estudos de MaldonadoBlanco, Romero e Galán-Wong (2003) indicam uma melhor produção de proteínas Cry quando o oxigênio dissolvido está em torno de $26 \%$. Este valor é conseguido com uma agitação de $300 \mathrm{rpm}$ e aeração de $1 \mathrm{vvm}$ ou $500 \mathrm{rpm}$ e $0.6 \mathrm{vvm}$, para B. thuringiensis subespécie israelensis em um fermentador de 5 litros.

Embora muitos estudos sejam feitos analisandose os parâmetros individuais, o cultivo deve ser visto e estudado como um todo. Neste sentido destacase o método de superfície de resposta que permite uma análise mais ampla dos parâmetros, bem como o estudo da combinação destes fatores (HSU; WU, 2002).

\section{Conclusões}

Devido às características biológicas, $B$. thuringiensis destaca-se como a principal bactéria utilizada no controle biológico. No entanto, a utilização de produtos derivados desse entomopatógeno é menos difundida no Brasil que em países desenvolvidos, sendo necessária a divulgação de produtos, implementação de produções regionais, as quais diminuem o custo e o estabelecimento de incentivos para implantação de programas de manejo integrado de insetos (MIPs).

Apoio financeiro: Conselho Nacional de Desenvolvimento Científico e Tecnológico (CNPq) por meio de concessão de bolsa de mestrado.

\section{Referências}

ABDEL-HAMEED, A. A stirred tank culture of Bacillus thuringiensis $\mathrm{H}-14$ for production of the mosquitocidal $\delta$-endotoxin: matematical modelling and scalling-up strudies. World Journal of microbiology e Biotechnology, Oxford, v. 17, n. 9, p. 857-861, 2001.

ADAMS, T. T.; EITENAN, M. A.; HANEL, B. M. Solid state fermentation of broiler litter for production of biocontrol agents. Bioresource Technology, New York, v. 82, n. 1, p. 33-41, 2002.

ALVES, L. F.; ALVES; A. S. B.; PEREIRA, R. R.; CAPALBO, D. M. F. Production of Bacillus thuringiensis Berliner var. kurstaki grow in alternative media. Biocontrol Science and Technology, Abingdon, v. 7, n. 3, p. 377-383, 1997.

ALVES, S. B. Patologia e controle microbiano: vantagens e desvantagens. In: (Ed.). Controle microbiano de insetos. Piracicaba: Manole, 1998. 1163 p.

ARANTES, O. M. N.; VILAS-BÔAS, L. A.; VILASBÔAS, G. F. L. T. Bacillus thuringiensis: estratégias no controle biológico. In: SERAFINE, L. A.; BARROS, N. M.; AZEVEDO, J. L. (Org.). Biotecnologia: avanços na agricultura e na agroindústria. Caxias do Sul: Agropecuária, 2002. p. 269-293.

ARCAS, J.; YANTORO, O.; ERTOLA, R. A new medium for growth delta-endotoxin production by Bacillus thuringiensis var. kurstaki. Biotechnology Letters, London, v. 6, n. 8, p. 495-500, 1984. 
Effect of high concentration of nutrients on Bacillus thuringiensis cultures. Biotechnology Letters, London, v. 9, n. 2, p.105-110, 1987.

BECKER, N.; MARGALIT, J. Use of Bacillus thuringiensis israelensis again mosquitoes and black flies. In: ENTWISTLE, P. F; CORY, J. S.; BAILEY, M. J.; HIGGS, S. (Ed.). Bacillus thuringiensis, an environmental biopesticide: theory and practice. New York: Wiley, 1993. p. 147-170.

BIZARRI, M. F.; BISHOP, A. H.; DINSDALE; A.; LOGAN, N. A. Changes in the properties of Bacillus thuringiensis after prolonged culture in a rich medium. Journal of Applied Microbiology, Oxford, v. 104, n. 1, p. 60-69, 2008.

BRAR, S. K.; VERMA, M.; TYAGI, R. D.; VALÉRO J. R. Recent advances in downstream processing and formulations of Bacillus thuringiensis based biopesticides. Process Biochemistry, New York, v. 41, n. 2, p. 323-342, 2006.

BRAVO, A.; GILLB, S. S.; SOBERÓN, M. Mode of action of Bacillus thuringiensis Cry and Cyt toxins and their potential for insect control. Toxicon, Amsterdam, v. 49, n. 4, p. 423-435, 2007.

BRAVO, A.; SOBERÓN, M. How to cope with insect resistance to Bt toxins? Trends in Biotechnology, London, v. 26, n. 10, p. 573-579, 2008.

CAPALBO, D. M. F.; VILAS-BÔAS, G. T.; ARANTES, O. M. N. Bacillus thuringiensis: formulações e plantas transgênicas. In: BORÉM, A. (Ed.). Biotecnologia e meio ambiente. Viçosa: Folha de Viçosa, 2004. p. 309-350.

CHANG, M.; SHUN-GUI-ZHOU, E.; LU, E. N.; NI, J-R. Starch processing wastewater as a new medium for production of Bacillus thuringiensis. World Journal of Microbiology \& Biotechnology, Oxford, v. 24, n. 4, p. 441-447, 2008.

CHEN, S; HONG, E. J.-Y.; WU, E. W-T. Fed-batch culture of Bacillus thuringiensis based on motile intensity. Journal of Industrial Microbiology and Biotechnology, Basingstoke, v. 30, n. 12, p. 677-681, 2003.

COUCH, T. L.; ROSS, D. A. Production and utilization of Bacillusthuringiensis.BiotechnologyandBioengineering, New York, v. 22, n. 7, p. 1297-1304, 2004.

$\mathrm{COUCH}, \mathrm{T}$. L. Industrial fermentation and formulation of entomopathogenic bacteria. In: CHARLES, J. F. (Org.). Entomopathogenic bacteria: from laboratory to field applications. New York: Kluwer Academic Publishes, 2000. p. 297-316.
CRICKMORE, N.; ZEIGLER, D. R.; FEITELSON, J.; SCHNEPF, E.; VAN RIE, J.; LERECLUS, D.; BAUM, J.; DEAN, D. H. Revision of the nomenclature for the Bacillus thuringiensis pesticidal crystal proteins. Microbiology and molecular biology review, Washington, v. 62 , n. 3, p. $807-813,1998$.

CRICKMORE, N.; ZEIGLER, D. R.; SCHNEPF, E.; VAN RIE, J.; LERECLUS, D.; BAUM, J.; BRAVO, A.; DEAN, D. H. Bacillus thuringiensis toxin nomenclature. Disponível: <http://www.lifesci.sussex.ac.uk/Home/ Neil_Crickmore/Bt/>. Acesso em: 24 dez. 2008.

DEVI, P. S. V.; RAVINDER, T.; JAIDEV, C. Barleybased medium for the cost-effective production of Bacillus thuringiensis. World Journal of Microbiology \& Biotechnology, Oxford, v. 21, n. 2, p. 173-179, 2005.

ESTRUCH, J. J.; WARREN, G. W.; MULIS, M. A.; NYE, G. J.; CRAIG, J. A.; KOZIEL, M. G. Vip3A, a novel Bacillus thuringiensis vegetative insecticidal protein with a wide spectrum of activities against lepidopteran insects. Proceedings of the National Academy of Sciences of the United States of America, Washington, v. 93, n. 11, p. 5389-5394, 1996.

FORATTINI，O. P.; KAKITANI，I.; MASSAD， E.; MARUCCI,D. Studies on mosquitoes (Diptera:Culicidae) and anthropic environment. 9-Synanthropy and epidemiological vector role of Aedes scapularis in southEastern Brazil. Revista de Saúde Publica, São Paulo, v. 29, n. 1, p. 199-207. 1995.

GHRIBI, D.; ZOUARI, N.; JAOUA, S. Improvement of bioinsecticides production through adaptation of Bacillus thuringiensis cells to heat treatment and $\mathrm{NaCl}$ addition. Journal of Applied Microbiology, Oxford, v. 98, n. 4, p. 823-831, 2005.

GLARE, T. R.; O'CALLAGHAN, M. Bacillus thuringiensis biology, ecology and safety. Chichester: John Wiley \& Sons, 2000, 350 p.

HABIB, M. E. M.; ANDRADE, C. F. S. Bactérias entomopatogênicas. In: ALVES, S. B. (Coord.). Controle microbiano de insetos. Piracicaba: Manole, 1986. p. 130140.

Bactérias entomopatogênicas. In: ALVES, S. B. (Coord.). Controle microbiano de insetos. Piracicaba: Manole, 1998. p. 383-446.

HSU, Y.; WU, W. A novel approach for scaling-up a fermentation system. Biochemical Engineering Journal, Amsterdam, v. 11, n. 2/3, p. 123-130, 2002.

IÇGEN, Y.; IÇGEN, B.; ÖZCENGIZ, G. Regulation of crystal protein biosynthesis by Bacillus thuringiensis: I Effects of mineral elements and $\mathrm{pH}$. Research in Microbiology, Paris, v. 153, n. 9, p. 599-604, 2002a. 
Regulation of crystal protein biosynthesis by Bacillus thuringiensis: II effects of carbon and nitrogen sources. Research in Microbiology, Paris, v. 153, n. 9, p. 605-609, 2002b.

LACHHAB, K.; TYAGI, R. D.; VALÉRO, J. R. Production of Bacillus thuringiensis biopasticides using wastewaters sludge as raw material: effect of inoculum and sludge solids concentration. Process Biochemistry, New York, v. 37, n. 2, p. 197-208, 2002.

LEREClUS, D.; DELÉCluSE, A.; LECADET, A. A. Diversity of Bacillus thuringiensis toxins and genes. In: ENTWISTLE, P. F.; CORY, J. S.; BAILEY, M. J.; HIGGS, S. (Ed.). Bacillus thuringiensis, an environmental biopesticide: theory and practice. New York: Wiley, 1993. p. 37-70.

MALDONADO-BLANCO, M. G.; ROMERO, G. S.; GALÁN-WONG, L. J. The effect of oxygen tension on the production of Bacillus thuringiensis supbs. israelensis toxin active agains Aedes aegypti larvae. World journal of Microbiology \& Biotechnology, Oxford, v. 19, n. 7, p. 671-674, 2003.

MONTIEL, M. L. T.; TYAGI, R. D.; VALERO, J. R. Wastewaters treatment sludge a raw material for the production of Bacillus thuringiensis based biopesticides. Water Ressearch, Oxford, v. 35, n. 16, p. 3807-3816, 2001.

MORAES, I. O.; CAPALBO, D. M. F.; ARRUDA, R. O. M. Produção de bioinseticidas. In: LIMA. U.A.; AQUARONE, E.; BORZANI; W.; SCHMIDELL, W. (Coord.). Biotecnologia industrial: processos fermentativos e enzimáticos. Porto Alegre: Edgar Blücher, v. 3, 2001. p. 245-265.

MORRIS, O. N.; KANAGARATNAM, P.; CONVERSE, V. Suitability of 30 agricultural products and by-products as nutrient sources for laboratory production of Bacillus thuringiensis subsp. Aizawai (HD133). Journal of invertebrate pathology, Orlando, v. 70, n. 2, p. 113-120, 1997.

NAIR, M. S.; DEAN, D. H. All domains of cryla toxins insert into insect brush border membranes. The Journal of Biological Chemistry, Baltimore, v. 283, n. 39, p. 26324-26331, 2008.

OHBA, M.; CRICKMORE, N.; CÔTÉ, J. C.; NAGAMATSU, Y.; KITADA, S.; SAKAI, H.; HARATA, K.; SHIN, T. Parasporin nomenclature. Disponível em: $<$ http://parasporin.fitc.pref.fukuoka.jp/>. Acesso em: 30 dez. 2008.

ÖSKAN, M.; DILEK, F. B.; YETIS, U.; ÖZCENGIZ, O. Nutritional and cultural parameters influencing antidpteran delta-endotoxin production. Research in Microbiology, Paris, v. 154, n. 1, p. 49-53, 2003.

POOPATHI, S.; KUMAR, K. A. Novel fermentation media for production of Bacillus thuringiensis subsp. israelensis. Journal of Economic Entomology, Lanham, v. 96, n. 4, p. 1039-1044, 2003.

POOPATHI, S.; KUMAR, K. A.; KABILAN, L.; SEKAR, L. Development of low cost media for the culture of mosquito larvicides, Bacillus sphaericus and Bacillus thuringiensis sorovar. Israelensis. World Journal of Microbiology \& Biotechnology, Oxford, v. 18, n. 3, p. 209-216, 2002.

PRABAGARAN, S. R.; PAKSHIRAJAN, K.; SWAMINATHAN, T.; JAYACHANDRAN, S. Media optimization of Bacillus thuringiensis PBT-372 using response surface methodology. Chemical and Biochemical Engineering Quarterly, Zagreb, v. 18, n. 2, p. 183-187, 2004.

PRABAKARAN, G.; BALARAMAN, K. Development of a cost-effective medium for the large scale production of Bacillus thuringiensis var. israelensis. Biological Control, Orlando, v. 36, n. 1, p. 288-292, 2006.

PRABAKARAN, G.; HOTI, S. L.; MANONMANI, A. M.; BALARAMAN, K. Coconut water as a cheap source for the production of $\delta$-endotoxin of Bacillus thuringiensis var. israelensis, a mosquito control agent. Acta Tropica, New York, v. 105, n. 1, p. 35-38, 2008.

RAYMOND, B.; LIJEK, R. S.; GRIFFITHS, R. I.; BONSALL, M. B. Quantifying the reproduction of Bacillus thuringiensis HD1 in cadavers and live larvae of Plutella xylostella. Journal of Invertebrate Pathology, Orlando, v. 98, n. 1, p. 307-313, 2008.

SALAMA, H. S.; MARGALIT, J. The use of Bacillus thuringiensis israelensis in development countries. In: ENTWISTLE, P. F.; CORY, J. S.; BAILEY, M. J.; HIGGS, S. (Ed.). Bacillus thuringiensis, an environmental biopesticide: theory and practice. New York: Wiley, 1993. p. 237-254.

SCHNEPF,E.; CRICKMORE,N.; RIE, J.V.;LERECLUS, D.; BAUM, J.; FEITELSON, J.; ZEIGLER, D. R.; DEAN, D. H. Bacillus thuringiensis and its pesticidal crystal proteins. Microbiology and Molecular Biology Review, Washington: [s.n.], v. 62, p. 775-806, 1998.

SERUFO, J. C.; OCA, H. M.; TAVARES, V.; SOUZA, A. M.; ROSA, R. V.; JAMAL, M. C. Isolation of dengue virus type 1 from larvae of Aedes albopictus in Campos Altos City, State of Minas Gerais, Brazil. Memórias do Instituto Oswaldo Cruz, Rio de Janeiro, v. 88, n. 3, p. 503-504, 1993. 
SHI, Y.; XU, W.; YUAN, M.; TANG, M.; CHEN, J.; PANG, Y. Expression of vip1/vip2 genes in Escherichia coli and Bacillus thuringiensis and the analysis of their signal peptides. Journal of Applied Microbiology, Oxford, v. 97, n. 4, p. 757-765, 2004.

TALUIL, P. L. Controle de doenças transmitidas por vetores no sistema único de saúde. Informativo Epidemiológico SUS, Brasília, v. 11, n. 2, p. 59-60, 2002.

TAMEZ-GUERRA， P.; GALÁN-WONG， L. J.; MEDRADO-ROLDÁN, H.; GARCÍA-GUTIÉRREZ, C.; RODRÍGUEZ-PADILLA, C.; GÓMEZ-FLORES, R. A.; TAMEZ-GUERRA, R. S. Bioinsecticidas: su empleo, producción y comercialización em México, Ciência UANL, San Nicolás de los Garzas, v. 4, n. 2. p. 143-152, 2001.

VALLEJO, F.; GONZÁLEZ, A.; POSADA, A.; RESTREPO, A.; ORDUZ, S. Production of Bacillus thuringiensis subsp. medellin by batch and fed-batch culture. Biotechnology Techniques, Kew, v. 13, n. 4, p. 279-281, 1999.

VALLETE-GELLY, I.; LEMAITRE, B.; BOCCARD, F. Bacterial strategies to overcome insect defenses. Nature Reviews: Microbiology, London, v. 6, n. 4, p. 302-313, 2008.

VIDYARTHI, A. S.; TYAGIA, R. D.; VALEROB, J. R.; SURAMPALLI, R. Y. Studies on the production of $B$. thuringiensis based biopesticides using wastewaters sludge as a raw material. Water Ressearch, Oxford, v. 36, n. 19, p. 4850-4860, 2002.

VILAS-BÔAS, G. T.; PERUCA, A. P. S.; ARANTES, O. M. N. Biology and taxonomy of Bacillus cereus, Bacillus anthracis and Bacillus thuringiensis. Canadian Journal of Microbiology, Ottawa, v. 53, n. 1, p. 673-687, 2007.

VORA, D.; SHETNA, Y. I. Enhanced growth, sporulation and toxin production by Bacillus thuringiensis subsp kurstaki in oil seed meal extract media contain cystine. World Journal Of Microbiology \& Biotechnology, Oxford, v. 15, n. 6, p. 747-749. 1999.

WU, W.; HSU, Y. L.; KO, Y. F.; YAO, L. L. Effect of shear stress on cultivation of Bacillus thuringiensis for thuringiensin production. Applied Microbiology Biotechnology, Heidelberg, v. 58, n. 1, p. 175-177. 2002.

YEZZA, A.; TYAGI, R. D.; VALÉRO, J. R.; SURAMPALLI, R. Y. Wastewaters sludge pre-treatment for enhancing entomotoxicity produced by Bacillus thuringiensis var. kurstaki. World Journal of Microbiology \& Biotechnology, Oxford, v. 21, n. 6/7, p. 1165-1174, 2005.

Bioconversion of industrial wastewaters and wastewaters sludge into Bacillus thuringiensis based biopesticides in pilot fermentor. Bioresource Technology, New York, v. 97, n. 15, p. 1850-1857, 2006.

YU, C. G.; MULLINS, M. A.; WARREN, G. W.; KOZIEL, M. G.; ESTRUCH, J. J. The Bacillus thuringiensis vegetative insecticidal protein vip3a lyses midgut epithelium cells of susceptible insects. Applied and Environmental Microbiology, Washington, v. 63, n. 2, p. 532-536, 1997.

ZOUARI, N.; JAOUA, S. The effect of complex carbon, and nitrogen, salt, tween- 80 and acetate on delta- endotoxin production by Bacillus thuringiensis subsp kurstaki. Journal of Industrial Microbiology \& Biotechnology, New York, v. 23, n. 6, p. 497-502. 1999. 